\title{
RECRYSTALLIZATION IN THE METAL OF WELDING JOINTS OF STEAM TRUCKS
}

\author{
V.V. Dmytryk, A.V. Glushko, A.K. Tsaryk \\ National Technical University "Kharkiv Polytechnic Institute", \\ E.O. Paton Electric Welding Institute \\ Kharkiv, Ukraine \\ E-mail: alyonaglushko@gmail.com, tel.+38-066-312-51-99
}

The recrystallization process in the structure of welded joints of steam pipelines from heat-resistant pearlitic steels, operated for a long time under creep conditions $\left(T_{\mathrm{e}}=545 \ldots .585^{\circ} \mathrm{C}, P_{\mathrm{e}}=20 \ldots 25 \mathrm{MPa}\right)$, reduces their performance. Studying the peculiarities of the recrystallization process will allow slowing down its passage, which is important for increasing the service life of welded joints of steam pipelines, which are characterized by the presence of a certain structural heterogeneity.

\section{INTRODUCTION}

Recrystallization in welded joints are considered as a process of gradual elimination of separate fragments of grain boundaries and further elimination of the grain boundaries themselves, which leads to the formation of large grains.

The goal of this work is a theoretical justification of the recrystallization process as applied to the structure of welded joints of steam pipelines, which are used for a long time under creep conditions.

The mechanism of recrystallization in metal of welded joints of steam pipelines that work for a long time under creep conditions has distinctive features from recrystallization during annealing of colddeformed metal: recrystallization during annealing has an incubation period and occurs as the effect of grain growth by eliminating grain boundaries, as well as the formation and growth of stress-free germs. Recrystallization in the metal of welded joints does not have an incubation period, is characterized by the absence of nucleation and begins approximately after their production time of more than $270000 \mathrm{~h}$, and also proceeds relatively slowly in the future. Recrystallization in the metal of welded joints of steam pipelines is the most pronounced in areas of incomplete recrystallization, overheating, and fusion of the heataffected zone (HAZ).

Recrystallization are considered as a component of the effect of degradation of the structure, resulting in a decrease by about $15 \ldots 20 \%$ of the strength properties of the metal of welded joints, as well as by $15 \ldots 20 \%$ of toughness [1-3].

\section{MATERIALS AND EXPERIMENTAL TECHNIQUES}

In this work, steels $12 \mathrm{Kh} 1 \mathrm{M} 1 \mathrm{~F}$ and $15 \mathrm{Kh} 1 \mathrm{M} 1 \mathrm{~F}$ were used. Accordingly, the operating temperature should not exceed $570 \ldots 580^{\circ} \mathrm{C}$.

Chemical composition of heat-resistant pearlitic steel 12X1MF, \%: C $-0.10 \ldots 0.15 ; \mathrm{Si}-0.17 \ldots 0.37$; $\mathrm{Mn}-0.40 \ldots 0.70 ; \mathrm{Cr}-0.90 \ldots 1.20 ; \mathrm{Mo}-0.25 \ldots 0.35$; $\mathrm{V}-0.15 \ldots 0.30 ; \mathrm{Ni}$ no more than $0.25 ; \mathrm{Cu}$ no more than 0.20 ; S no more than 0.025 ; $\mathrm{P}$ no more than 0.025 . Chemical composition of heat-resistant pearlitic steel 15Kh1M1F, \%: C - 0.10..0.16; Si - 0.15...0.37; Mn -
$0.40 \ldots 0.70 ; \mathrm{Cr}-1.10 \ldots 1.40 ; \mathrm{Mo}-0.90 \ldots 1.10 ; \mathrm{V}-$ $0.20 \ldots 0.35$; Ni no more than 0.25 ; $\mathrm{Cu}$ no more than 0.20 ; S no more than 0.025 ; P no more than 0.025 .

The experimental technique included the use of optical and electron microscopy. The study of dislocations in $\alpha$-phase grains (matrix ferrite and bainite tempering) was performed using the thin foil method. By using a scanning electron microscope JSM-820 with an X-ray microanalyzer system LINK AN101856, the chemical composition of the phase grains, carbides, and non-metallic inclusions was determined.

\section{RESULTS AND DISCUSSIONS}

Recrystallization occurs while simultaneously reducing the level of the lattice distortion by diffusion of the alloying elements from the central regions of the crystal to their border regions, which contributes to the subsequent increase in its deformation. The recrystallization process begins to manifest itself when the metal is deformed from approximately $2 \ldots 3 \%$, which is typical for areas of incomplete recrystallization, overheating, and fusion of the HAZ. The base metal, as well as the weld metal and the metal of other HAZ sites, when welded joints reach more than $270000 \mathrm{~h}$, usually deforms less than $1 \%$, and there is no noticeable manifestation of recrystallization in their structure.

During long-term operation in the metal of welded joints, self-diffusion ensures the formation in the border zones of $\alpha$-phase grains of segregations from chromium, molybdenum, silicon and manganese elements [1, 2], which leads to a decrease in the level of crystal distortion, and at the same time increases its deformation capacity. In the process of long-term development under creep conditions, the original structure of welded joints is transformed into a ferritecarbide mixture. In the process of crystal deformation, elimination and partial displacement of high-angle grain boundaries occurs. Recrystallization is preceded by a return, which includes the rearrangement of dislocations, their nucleation, recombination, and annihilation. Under creep conditions, "static" recrystallization takes place, leading to the elimination of grain boundaries, which is ensured by the desire to possess less free energy. The growth of individual grains occurs due to the elimination of grain boundaries (Fig. 1). There is a restructuring of the structural state of 
the grains in the presence of plastic deformation. The deformation of the metal of the HAZ sections, as well as the weld metal and the base metal of welded joints, when operating for $250000 \ldots 280000 \mathrm{~h}$, is different and consists of: overheating section $1 \ldots 3 \%$, incomplete recrystallization $3 \ldots 7 \%$, base metal $0.3 \ldots 0.5 \%$, weld metal $0.4 \ldots 0.6 \%[2,3]$.

The recrystallization process in the structure of welded joints is facilitated by carbide reactions $\mathrm{M} 3 \mathrm{C} \rightarrow$ M7C3 $\rightarrow$ M23C6, the separation of grain boundaries from carbides, dislocation displacements and their interaction [1-4]. Together, these factors lead first to a local one (see Fig. 1), and then to the complete elimination of individual grain boundaries (Fig. 2).

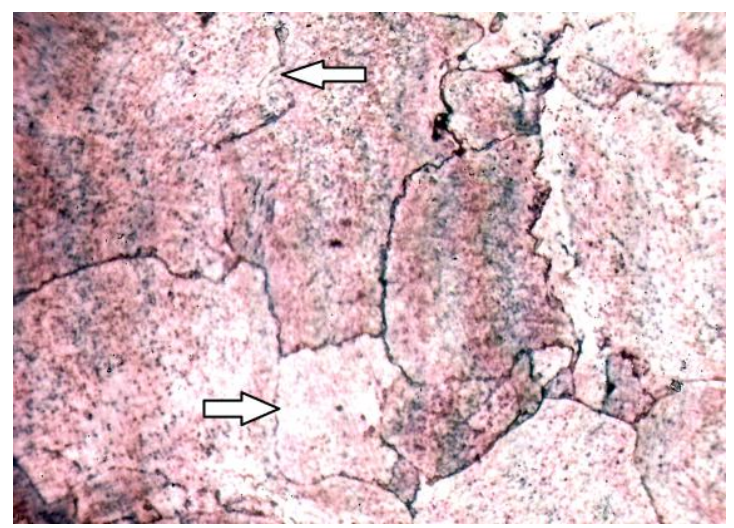

Fig. 1. Structure of the HAZ overheating section. The elimination of fragments of grain boundaries is indicated by arrows. Welded joint from steel 12 XIMF. Working hours $280000 \mathrm{~h}, x 300$

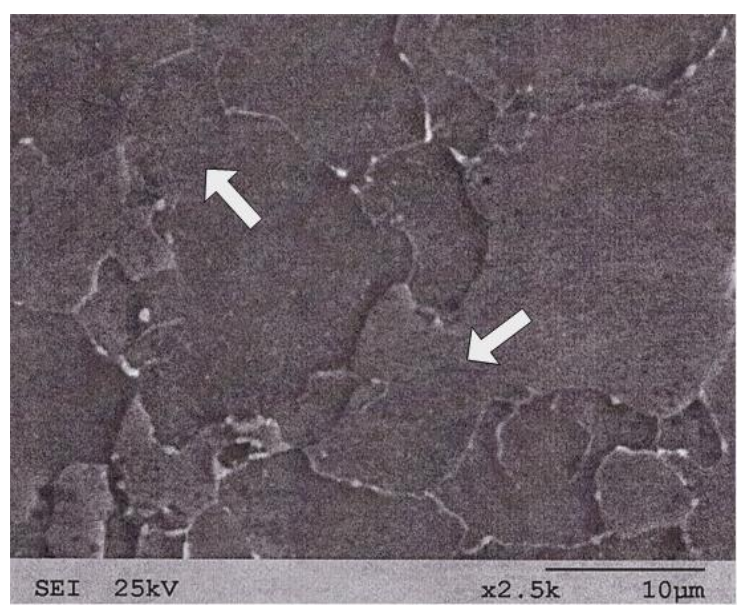

Fig. 2. Structure of the HAZ overheating section.

The intergranular boundaries that have been eliminated are indicated by arrows.

Welded joint from steel $15 X 1 M 1 \mathrm{~F}, 286000 \mathrm{~h}$

The presence in the crystal of the $\alpha$-phase of the substitutional elements (chromium, molybdenum, vanadium), as well as "sedentary" dislocations, ensures its uneven deformation. Different density of dislocations on the body of grains and on their boundaries, incl. near the discharge of the second phases [4], provides a different level of strain accumulation, which seems to be an integral part of the energy factor of their movement.

Recrystallization in the metal of welded joints has no separation into primary, collective, secondary. The recrystallization process under consideration is characterized by an increase in the grain size. Their increase occurs at different rates in the presence of a characteristic structure, respectively, for each HAZ site, as well as the weld metal and the base metal. Grain growth occurs by eliminating grain boundaries (see Figs. 1 and 2). In the process of their merging, the shape of the grains acquires a gradual change. The rate of elimination of grain boundaries is the highest in the area of incomplete recrystallization of HAZ, where new austenite decomposition products represent globulized perlite (Fig. 3).

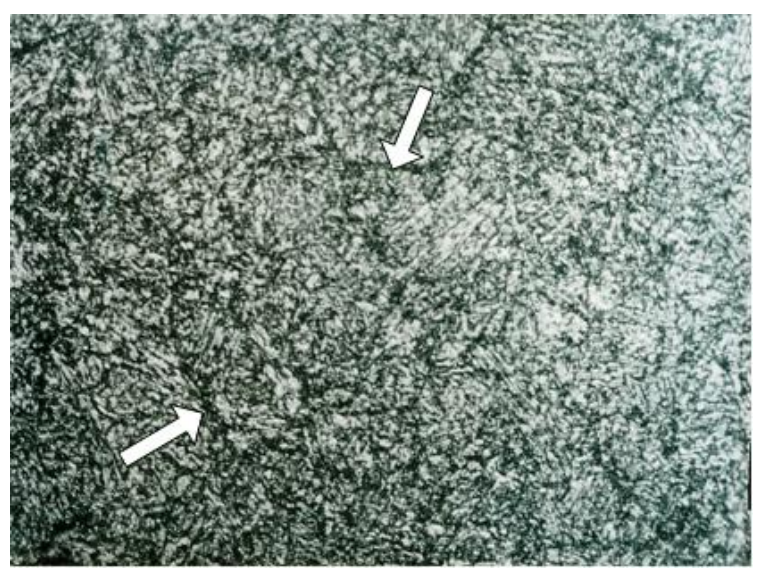

Fig. 3. Structure of the site of incomplete recrystallization of $H A Z$. New austenite decomposition products represent globularized perlite (indicated by arrows). Welded joint from steel $15 \mathrm{Kh} 1 \mathrm{M1F}, \mathrm{x} 360$

The work of eliminating, under creep conditions, grain boundaries can be considered as the applied energy and the Gibbs energy difference $G$ of two contacting grains per unit volume of the grain boundary $\left(\mathrm{J} / \mu \mathrm{m}^{3}\right)$.

The reduction of the energy level of the system state (grain boundary) depends on its structure, and is also ensured by the joint manifestation of work, both external and internal forces. When studying the features of eliminating intergranular boundaries, a reference system was adopted, i.e. its initial position (Fig. 4).

It was assumed that the $E$ fragment in the $S_{1}$ reference system provides for the elimination of the intergranular boundary with the progressive velocity $V$ relative to the $S_{2}$ reference system. We write:

$$
E=E^{\prime}+\frac{1}{2} m V^{2}+P^{\prime}
$$

where $P^{\prime}=m V^{\prime}$ is the momentum of the fragment in the system $S^{\prime} ; m$ is the mass of the fragment of the intergranular boundary.

It was taken into account that when eliminating grain boundaries, the Gibbs energy decreases, respectively. Imagine:

$$
d G=\left[-\bar{P}_{1}+\left(-P_{2}\right)\right] d A d x=-\bar{P}_{3} d v,
$$

where $d v$ is the changed volume of the grain with the elimination of a fragment of the grain boundary; $A$ is the element of the fragment. 

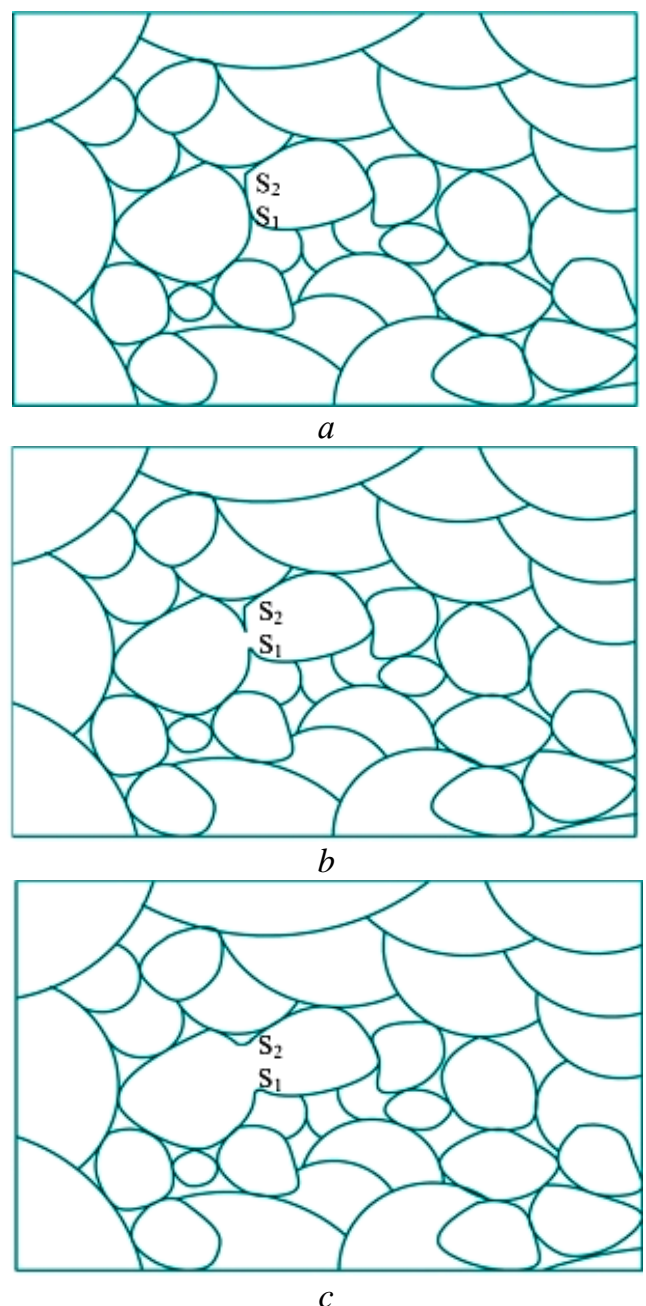

Fig. 4. Schematic representation of the successive elimination of grain boundaries: $a$ - the initial state of the structure; $b$-fragment of elimination of the intergranular boundary; $c$-complete elimination of the grain boundary; $S_{1}-S_{2}$ - the reference system

The driving force, under creep conditions, is the local manifestation of free energy per unit volume $\bar{P}_{1}$ and energy $\bar{P}_{2}$, as an effect of the operating voltage $P_{1}+P_{2}=-\frac{d G}{d v}$.

In the process of recrystallization, the acting force ensuring the elimination of grain boundaries is the accumulated energy of the existing "sedentary" as well as the resulting dislocations. At the initial stage of recrystallization, the driving force is the energy of the grain boundaries. It was established that the dislocation density at the boundary areas of the contacting grains is $10^{12}$, and $10^{10} \mathrm{~m}^{-2}$ along their body.

To determine the volume fraction of the recrystallized structure $f(t)$ during time $\mathrm{t}$, an expression was proposed:

$$
f(t)=1-e^{\beta V_{1} V_{2} t^{k}}
$$

where $\beta$ is the correction factor; $V_{l}$ is the rate of formation of fragments of elimination of grain boundaries; $V_{2}$ - fragment growth rate; $2<k<4$.
The proposed relationship provides a curve (Fig. 5), which corresponds to the operating time of the welded joint of the steam line, in creep conditions, of $280000 \mathrm{~h}$.

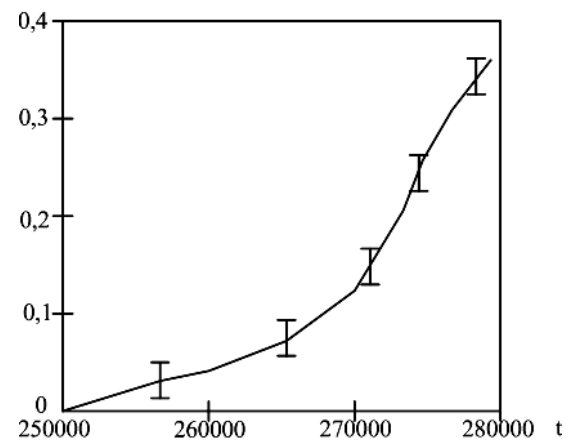

Fig. 5. Dependence of metal recrystallization of the HAZ overheating area on time $t$. Welded joint from steel $15 X 1 M 1 F$

The elimination of grain boundaries occurs simultaneously with the formation of segregations (from replacement elements), the separation of the second phases $\mathrm{Mo}_{2} \mathrm{C}$ and $\mathrm{VC}$, coagulation of $\mathrm{M}_{7} \mathrm{C}_{3}$ and $\mathrm{M}_{23} \mathrm{C}_{6}$. The diffusion movement of chromium and molybdenum from the central regions of the grains to their border areas also contributes to the elimination of grain boundaries. It was established that in the process of eliminating grain boundaries, their fragments are eliminated first, and then the boundaries themselves (see Figs. 1,2). In the recrystallization process, the intergranular boundaries are initially eliminated, which are exposed to the applied relative to the highest operating voltage, which depends on their shape, location, type of structure and level of deformation of the contacting grains.

The local elimination of fragments of grain boundaries (operating time over $270000 \mathrm{~h}$ ) is not accompanied by a simultaneous change in the different structural orientations of both grains to the same.

Accelerations of up to $600 \ldots 650^{\circ} \mathrm{C}$ (emergency steam discharge) contribute to the acceleration (by about $10 \ldots 15 \%$ ) of the recrystallization process, which allows the process to be considered as thermally activated. The passage of the process in time, which is confirmed by the data (see Fig. 5), is: $t=A \cdot e^{\frac{Q}{R T}}$, where $A$ is a constant; $Q$ is the activation energy of the recrystallization process; $T$ is the temperature; $R$ is the gas constant.

The magnitude of the activation energy of recrystallization depends on the structural state of welded joints, as well as on the conditions of their operation. Allowed overheating leads to a certain acceleration of the recrystallization process. It is important to establish the dependence of the onset of recrystallization on the level of deformation of the metal of welded joints and the presence of segregations, which manifests itself on the internal surfaces of grain separation (subgrain boundaries), as well as in the border zones of the grains [1-4]. Mostly, the presence of segregation is typical for HAZ sites: incomplete recrystallization (where new austenite decomposition products represent globulized perlite (see Fig. 3)) and 
overheating (where the austenitic grain is less than 4th, GOST 5639-82). The formation of segregations occurs with simultaneous creeping of dislocations, which leads to the local elimination of grain boundaries. It makes sense to establish the onset of recrystallization with the presence of segregations.

Most intensively, in welded joints of steam pipelines, recrystallization occurs in the structure of the section of incomplete recrystallization of HAZ, where fine-grained globulized perlite is present (see Fig. 3), grouped as discontinuous chains in a ferrite-bainite, ferrite-sorbitol, or ferrite-reed structure. Average grain size -9 . With a slightly lower activity (about $20 \ldots 30 \%$ ), the recrystallization process takes place in the overheating area, where the structure is characterized by the presence of grains of various sizes (Fig. 6). Average grain size-3. Grains in the overheating area belong to the same structural type, which ensures a reduction in the level of recrystallization.

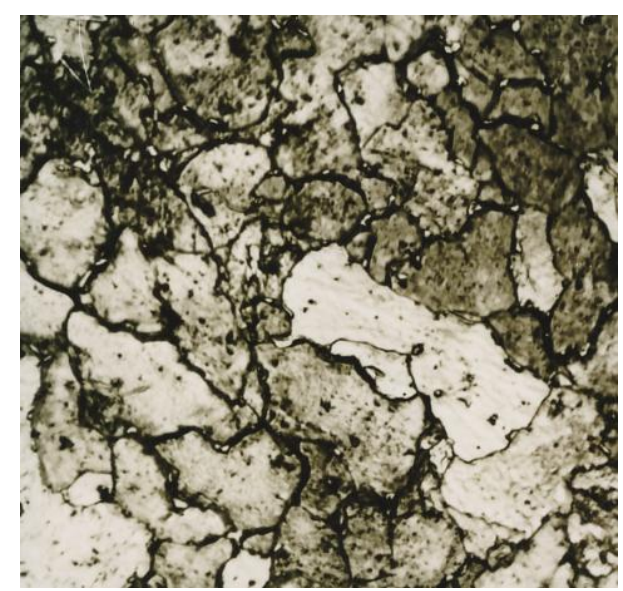

Fig. 6. The structure of the HAZ overheating section. Welded joint from steel $15 X 1 M 1 F$. Working hours $280000 \mathrm{~h}, x 400$

The study of the recrystallization mechanism made it possible to reveal its manifestation in the metal of longterm operated welded joints of steam pipelines. The revealed features of the mechanism of the recrystallization process can be represented in a grouped form:
- elimination of grain boundaries occurs depending on the applied voltage and their location;

- the rate of elimination of grain boundaries depends on their structural state;

- elimination of grain boundaries is accelerated in the presence of overheating (temperature is higher than the recommended regulatory documentation);

- the merging of the grains leads to the subsequent formation of the same structural orientation of the merged, by coaliscence, grains.

We believe that the mechanism of the process of recrystallization of metal of welded joints of steam pipelines, under creep conditions, should be supplemented by invoking the provisions of the theory of dislocations and the theory of grain boundaries.

\section{CONCLUSION}

1. Theoretically substantiated the peculiarities of the recrystallization process in the metal structure of welded joints of steam pipelines, which are operated for a long time under creep conditions.

2. Developed a model of the recrystallization process, taking into account the dependence of its passage on the structural state and on the level of deformation of the metal of welded joints, which work for a long time under creep conditions.

3. The dependence of the recrystallization rate on the structural state of welded joints and the conditions of their operation was established.

\section{REFERENCES}

1. В.В. Дмитрик, В.Н. Баумер. Металлофиз. новейшие технологии. 2007, v. 29, №7, p. 937.

2. В.В. Дмитрик, С.Н. Барташ. Металлофиз. новейшие технологии. 2010, v. 32, №12, p. 1657.

3. В.В. Дмитрик, А.В. Глушко, Т.А. Сыренко, С.Г. Григоренко. Автоматическая сварка. 2018, №5, p. 9.

4. A. Glushko // Eastern-European Journal of Enterprise Technologies, 2016, v. 6, N 1(84), p. 14; DOI: $10.15587 / 1729-4061.2016 .85852$.

5. А.В. Глушко, В.В. Дмитрик, Т.А. Сыренко. Металлофиз. новейшие технологии. 2018, v. 40, №5, p. 683 .

Article received 19.08.2019

\section{РЕКРИСТАЛЛИЗАЦИЯ В МЕТАЛЛЕ СВАРНЫХ СОЕДИНЕНИЙ ПАРОПРОВОДОВ}

\section{В.В. Дмитрик, А.В. Глуико, А.К. Царюк}

Процесс рекристаллизации в структуре сварных соединений паропроводов из теплоустойчивых перлитных сталей, длительно работающих в условиях ползучести $\left(T_{\ni}=545 \ldots 585{ }^{\circ} \mathrm{C}, P_{\ni}=20 \ldots 25 \mathrm{MПа}\right)$, способствует снижению их эксплуатационных характеристик. Изучение особенностей процесса рекристаллизации позволит замедлить его прохождение, что актуально для увеличения ресурса сварных соединений паропроводов, характеризующихся наличием определенной структурной неоднородности.

\section{РЕКРИСТАЛІЗАЦІЯ В МЕТАЛІ ЗВАРНИХ З'СДНАНЬ ПАРОПРОВОДІВ}

\section{В.В. Дмитрик, А.В. Глуико, А.К. Царюк}

Процес рекристалізації в структурі зварних з'єднань паропроводів із теплостійких перлітних сталей, які тривалий час працюють в умовах повзучості $\left(T_{\mathrm{e}}=545 \ldots 585^{\circ} \mathrm{C}, P_{\mathrm{e}}=20 \ldots 25 \mathrm{MПа}\right)$, сприяє зниженню їх експлуатаційних характеристик. Вивчення особливостей процесу рекристалізації дозволить уповільнити їх проходження, що актуально для збільшення ресурсу зварних з'єднань паропроводів, що характеризуються наявністю певної структурної неоднорідності. 